\title{
TRAUMA E REPRESENTAÇÃO: REFLEXÕES SOBRE O CONTEXTO DO INCÊNDIO NA BOA- TE KISS
}

VOLNEI ANTONIO DASSOLER UNIVERSIDADE FEDERAL DO RIO GRANDE DO SUL

PORTO ALEGRE, RIO GRANDE DO SUL, BRASIL DASSOLER@TERRA.COM.BR 


\section{TRAUMA E REPRESENTAÇÃO: REFLEXÕES SOBRE O CONTEXTO DO INCÊNDIO NA BOATE KISS}

Resumo: $O$ artigo propõe uma reflexão sobre algumas narrativas suscitadas a partir do contexto do incêndio na Boate Kiss e compreendidas como esforço de representação e transmissão deste acontecimento enquanto experiência traumática individual e coletiva. Para tanto, consideramos os diferentes modos de implicação e testemunho produzidos neste cenário como possibilidade de elaboração.

Palavras-chave: Trauma; Solidariedade; Representação

\section{TRAUMA Y REPRESENTACIÓN: REFLEXIONES SOBRE EL CONTEXTO DEL INCENDIO EN BOATE KISS}

Resumen: El artículo propone una reflexión sobre algunas narraciones suscitadas a partir del contexto del incendio en la Boate Kiss y comprendidas como esfuerzo de representación y transmisión de este acontecimiento como experiencia traumática individual y colectiva. Para ello, consideramos los diferentes modos de implicación y testimonio producidos en este escenario como posibilidad de elaboración.

Palabras clave: Trauma; La solidaridad; Representación

\section{TRAUMA AND REPRESENTATION: REFLECTIONS ON THE CONTEXT OF THE FIRE AT KISS NIGHTCLUB}

Abstract: The article proposes a reflection on some narratives raised from the context of the fire in the Kiss Nightclub and understood as effort of representation and transmission of this event as an individual and collective traumatic experience. Therefore, we consider the different modes of implication and testimony produced in this scenario as a possibility of elaboration.

Keywords: Trauma; Solidarity; Representation 


\section{INTRODUÇÃO}

Este artigo pretende recuperar alguns elementos que fizeram parte do contexto do incêndio na Boate Kiss ocorrido em 27 de janeiro de 2013 como base para novos diálogos com o tempo presente. Esta abordagem reconhece uma dimensão de complexidade envolvendo este acontecimento e seus desdobramentos e presume que as semelhanças encontradas com episódios da mesma natureza ao redor do mundo não são suficientes para tornar compreensíveis algumas particularidades locais.

Face a essa configuração e ao compromisso ético de transmissão e inscrição que tal acontecimento exige enquanto memória individual e coletiva, nos movimentamos dentro dos limites estruturais da narrativa em direção à capacidade possível de elaboração. Com efeito, o que seria possível dizer, hoje, sobre as manifestações de solidariedade e a subsequente exigência de superação reivindicada por parte da população? Como entender a perspectiva conceitual de trauma enquanto noção sujeita à singularidade num contexto de generalização típico de desastres de massa? E, por fim, mas não menos importante, qual lugar (ou quais lugares) ocupa a Associação dos Familiares de Vítimas e Sobreviventes da Tragédia de Santa Maria (AVTSM) no discurso social local e na construção de memória?

\section{TRAUMA E SOLIDARIEDADE}

Uma das propriedades da linguagem é a sua capacidade de produzir de efeitos e de participar ativamente na operação diagnóstica da realidade. A partir deste entendimento, ressaltamos que este artigo não é um processo de análise definitiva acerca de um fato passado e historicamente datado, posicionando-se como um arranjo discursivo e analítico que visa extrair de que tal acontecimento algo que concerne a nós e ao nosso tempo. Para esse percurso, buscamos como referência o campo psicanalítico.

Passado mais de um século desde seu surgimento na cultura ocidental, a psicanálise, enquanto teoria e prática, refunda, permanentemente, sua condição de pertencimento à cultura. Esta permanência impõe ao analista que sua prática deve levar em conta, de maneira irredutível, a subjetividade da época em que vive acolhendo como legítimas as consequências subjetivas metamorfoseadas nas formas de viver (Lacan [1953]1998). Inserido na pólis e assumindo uma posição descrita por Laurent (2007) como “analista cidadão", o analista orienta-se pela ética da psicanálise, mos- 
trando-se sensível às formas de segregação, posicionando-se diante das vicissitudes do nosso tempo, participando ativamente das discussões sobre os processos de subjetivação na busca de compreender qual foi sua função e qual é que lhe corresponde hoje.

Um acontecimento qualificado como traumático caracteriza-se pelo caráter de violência e imprevisibilidade que o acompanham surpreendendo o sujeito que se vê exposto e envolvido neste drama. Para Freud ([1920]1995) está em jogo uma vivência de excesso, diante da qual o aparelho psíquico é confrontado com seu limite na capacidade de tramitar psiquicamente este montante de estímulo e energia. Assim, destituído dos recursos imaginários e simbólicos para acomodar as consequências da suspensão, provisória ou permanente, do funcionamento psíquico o sujeito afetado testemunha com seu sofrimento a impotência frente ao Outro'. As consequências disruptivas instalam um suspense onde havia uma rotina e o sujeito se vê numa condição de estranhamento com relação ao próprio Eu, colocando-se numa posição de desconfiança com relação ao Outro ao se perceber arrancado de um lugar ao qual nunca mais poderá retornar.

Faltam palavras, sentidos e representações para fazer borda ao que foi vivido, tornando evidente o caráter de desamparo que se inclui nesta experiência. No caso de um desastre de massa, esse entendimento se amplia à dinâmica social, favorecendo a generalização da noção de trauma e à consequente sensação de urgência à qual se associa. Segundo o psicanalista argentino, Guillermo Bellaga (2005), a urgência generalizada fala de um traumatismo, tanto em nível coletivo quanto singular, onde e quando nos deparamos com a impotência do discurso para ler o acontecimento, ou seja, quando as narrativas compartilhadas pela comunidade em um determinado tempo e lugar se mostram insuficientes para acomodar o acontecimento e seus efeitos. Como consequência deste encontro disruptivo, algo permanece fora do universo interpretativo que o sujeito e comunidade tem disponível.

1 Outro: conceito de Lacan que faz referência ao simbólico, naquilo que este registro se oferece como depositário de tudo o que pode ser dito e instância que preside as trocas no laço social, a despeito de permanecer alheio ao sujeito. (Lacan, [1955/1956]1988). Nesse sentido, o Outro nos constitui pela incidência da linguagem em nosso corpo através dos discursos que compõe a trama da cultural, por isso nos permitimos a falar em Outro social, da cultura, jurídico. 
Diante deste quadro de incontáveis adversidades suscitadas pelo incêndio na Boate Kiss, a população de Santa Maria se mobilizou numa imediata reação de solidariedade ofertando recursos materiais e simbólicos em diferentes níveis de necessidade. Tal iniciativa minimizou os efeitos deletérios da exposição traumática e cooperou para a manutenção de certa solidez e confiança no laço sociais emoldurando um cenário de solidariedade. Com isso, apesar da sensação de estranhamento vivida pela população, que se via dentro e fora do próprio acontecimento, muros, portas, janelas, casas e carros perderam seu caráter individual convertendo-se em espaços simbólicos e compartilhados livres para a circulação de todos. Esse modo de tratamento dos traumas de massa feito de maneira coletiva é um primeiro tempo necessário e parte de uma reação para lidar com tantas mortes, feridos e sequelas de diferentes naturezas, ou seja, diante de um fato traumático de alcance coletivo, o próprio coletivo é parte da reparação.

Nesse sentido, as manifestações e rituais coletivos que se sucederam ao incêndio testemunharam o cruzamento de um eixo vertical de apelo para a recuperação da consistência do Outro com um eixo horizontal pela identificação entre todas pessoas de que isso poderia ter acontecido comigo ou com alguém da minha família. Transitórios, esses movimentos sinalizaram o esforço de recuperação da potencialidade simbólica cujas formas de elaboração, por meio da cultura, funcionam como uma rede de proteção diante da reedição da condição de desamparo desencadeada pela tragédia. É nessa perspectiva que, diante de desastres e violências, atos de solidariedade se colocam como suplência à inconsistência do Outro e à crise generalizada do universal, funcionando a serviço da coletividade e do sujeito (SOLER, 2004), especialmente num mundo que não se funda mais sobre ideias totalizantes e universalizantes (BIRMAN, 2005).

Segundo Freud ([1921]1995), o semelhante é condição sine qua non para o surgimento da existência em sua dimensão humana, oferecendo-se tanto como suporte quanto como meio de acesso aos recursos de significação situando-se como modelo, objeto, auxiliar e rival. $O$ entendimento freudiano pressupõe que o desamparo é uma condição estruturante do ser humano presente desde o início da vida e que permanece inscrita na trajetória de cada um, não sendo, portanto, uma fase superável. Esta formulação nos permite pensar que a gestão do desamparo não é uma tarefa exclusivamente individual, fazendo-se com o apoio de estratégias coletivas e públicas, de maneira que o sujeito não se perceba sozinho para lidar com os destinos das 
pulsões, dos desejos e dos acontecimentos da existência, assegurando-lhe possibilidades de encontrar e inventar saídas singulares numa dimensão de inclusão no laço social.

Para a psicanálise, esta dinâmica intersubjetiva se estabelece através de um mecanismo identificatório que liga o sujeito situado na condição de vulnerabilidade com aquele que se oferece ao cuidado pela mediação da linguagem e do afeto. Diante de um desastre, quando o desamparo se recoloca em cena, as manifestações de solidariedade surgem como anteparo ao horror e a angústia decorrentes das perguntas que ficam sem respostas. Esta disposição ao acolhimento é impulsionada, segundo Freud ([1921]1995), pelo reconhecimento naquele que está vulnerável de uma posição subjetiva já vivenciada por aquele que se oferece ao cuidado. Nas palavras de Freud, esta identificação se instala por meio de um traço em comum entre ambos, ou seja, pela existência de "uma qualidade emocional comum". Seguindo nesta linha de raciocínio, concluímos que todo ato de solidariedade tem um fundamento no narcisismo, componente que, numa primeira leitura, não entra em desacordo quanto ao valor do ato solidário produtivo.

Contudo, reconhecemos a existência de práticas identificadas como solidárias, mas que atuam, essencialmente, através de ações que servem para demarcar territórios e lugares para o exercício de poder sobre alguém em condição de desvantagem (eu te dou o que você não tem para que fique grato a mim e, por minha parte, fico aliviado de qualquer culpa). Nesta mesma direção, atuam na reafirmação da supremacia de elementos imaginários distintivos (gênero, condição social, etc) favorecendo gestos de humilhação e estando muito distantes de uma prática de reconhecimento do outro enquanto alteridade.

\section{TRAUMA E ELABORAÇÃO}

Notadamente, no transcorrer do século XX, a noção de trauma foi se constituindo como um elemento importante para falar sobre a experiência humana na modernidade, em especial a partir de fenômenos de violência e desastres que comparecem no cotidiano da vida humana (FUKS, 2006). Tal proliferação ganhou usos pluralizados e habita com frequência cada vez maior os diferentes registros onde a emergência do mal-estar contemporâneo se faz presente, chegando ao ponto de se consolidar como significante corriqueiro no vocabulário e imaginário popular. 
Para problematizar a consistência deste discurso e seus efeitos performativos no processo de subjetivação, Didier Fassin e Richard Rechtman (2009) em seu livro The empire of trauma: inquiry into the condition of victimhood, vão buscar apoio nos conceitos foucaultianos de biopoder e biopolítica. Segundo os autores, a valorização desta lógica de saber e de fazer relativa ao trauma adquire contornos de uma política do trauma, na medida em que favorece a disseminação de uma abordagem individualizada do fenômeno, excluindo, na maior parte das vezes, elementos de caráter social que são componentes decisivos destes contextos, mas que restam fora desta compreensão.

A onipresença do discurso do trauma se mostrou inevitável no que se seguiu ao incêndio da Boate Kiss. Diante da violência do desastre, a realidade do acontecimento foi tomada como um fato em si, sendo interpretada como o elemento suficiente para a designação em massa do trauma. Neste contexto de generalização corre-se o risco de uma profusão de identidades traumáticas apoiadas por um conjunto discursivo pela disseminação do diagnóstico Transtorno de Estresse Pós-traumático (TEPT). Assim, o trauma é entendido como fato e não como processo. De maneira distinta, entendemos que o trauma não se define pelo acontecimento em si, mas pelas consequências que ressoam de modo único para cada pessoa. Esta é a dimensão de singularidade que propomos, a de que os efeitos de cada acontecimento se determinam para cada um de modo diferente.

A abordagem atual da noção de trauma surge como um paradigma clínico problemático ao traduzir o sofrimento e a experiência em termos unicamente de sintomas, escolha metodológica que reduz a complexidade dos fenômenos em quadros clínicos objetivos, individualizados e descontextualizados (LAURENT, 2014). Além disso, o caráter coletivo de um desastre não é prerrogativa suficiente para a recusa da concepção de singularidade em favor de identificações coletivas como recurso de tratamento. Assim, se por um lado, esta ampliação do uso do trauma promoveu o reconhecimento de situações de sofrimento subjetivo que estavam à margem, por outro, trouxe o risco de apagamento da dimensão subjetiva que se coloca como fator essencial no processo de elaboração do sujeito com vistas a recuperar certa imagem narcísica e localizar-se no mundo e na relação com os objetos e com os ideais

Por outro lado, precisamos estar advertidos de que a prática generalizante da noção de trauma que acompanhamos nas discussões no campo da 
saúde e nas abordagens midiáticas relativas a situações de violências (individuais ou coletivas) são mecanismos propícios para o estabelecimento de um contexto de anestesia na população atuando, indiretamente, para a sua assimilação a um cotidiano de indiferença, esvaziando a possibilidade transformadora e de implicação que seriam esperadas.

Trata-se, em última instância, da perspectiva que funda o discurso da "superação" repetido exaustivamente durante meses por parcela significativa da população, o que não quer dizer nada mais, nada menos do que a manifestação de um desejo de que tudo deveria voltar a ser como era antes o mais rápido possível. Esse aspecto é importante para esclarecer um tipo de discurso que vimos se reproduzir recorrentemente na cidade quanto à posição de relutância e de vitimização supostamente assumida por parte das pessoas atingidas pelo incêndio (sobreviventes e familiares) e que contrariava as expectativas de outros segmentos sociais. Segundo esta visão, as manifestações e protestos se colocariam contra a cidade ao manter viva a lembrança de um acontecimento que deveria ser esquecido por trazer consequências negativas para o desenvolvimento da cidade. Este recorte discursivo individualiza o acontecimento situando-o apenas nas pessoas diretamente envolvida e desimplicando a cidade como em todo.

Tendo acompanhado de perto muitos dos processos e acontecimentos relativos ao incêndio, testemunho que, desde o primeiro ano e dentro da possibilidade de cada um, pais, sobreviventes e demais pessoas envolvidas diretamente nas ações de resgate, saúde, segurança, tentaram voltar à rotina. Intimamente, ansiavam retomar o trabalho, estudar, namorar. Alguns viajaram, outros optaram pelo isolamento como modo terapêutico de sobrevivência, outros buscaram alternativas de lazer, inventaram novos ofícios, buscaram acompanhamento em saúde mental. Entretanto, se por um lado, a vida seguia as exigências do cotidiano, por outro lado, o enfretamento dessa nova realidade não se apresentou linear e, tampouco, poderia ser sem sobressaltos. Tristeza, pesadelos, dúvidas, culpas seguiam e seguem presentes, sem que isso autorize um julgamento de fraqueza moral justamente por deixar evidente a marca da humanidade à qual todos nós estamos submetidos.

Nesse sentido, a AVTSM ocupou e segue ocupando um lugar social essencial tanto para aqueles que representam quanto para ocupar o lugar de referência e diálogo na relação com a cidade. Ponto de ancoragem, diante de um contexto indefinido e tenso, seu protagonismo se fez claro e neces- 
sário desde o início. Com esta iniciativa, os pais, mães, familiares dão nome, criam um espaço de solidariedade e afeto e se constituem no mais importante mecanismo formal de apoio institucional com pautas em diversos registros: saúde, justiça, reparação econômica, memória, pesquisa, assistência social, dentre outras.

Desde então, a AVTSM opera na função de testemunhar a história e de garantir legitimidade pública às histórias das vítimas fatais, dos sobreviventes e dos familiares, sem pretender qualquer tipo de apego ao passado como forma de recusa ao presente e ao futuro. Sua existência é a própria resistência ao modo contemporâneo de banalização da violência e da insensibilidade à vida humana.

\section{CONSIDERAÇÕES FINAIS}

Este artigo trabalha algumas particularidades do trabalho de elaboração ligado ao incêndio na Boate Kiss cujas ações se fazem em dois registros de implicação: individual e coletivo. Desta maneira, a responsabilidade de transmissão deste acontecimento não é uma tarefa de cunho privado e íntimo, requerendo a partilha social como modo de tratamento para que tal conexão opere algo de curativo na relação com o trauma para os sujeitos e para a cidade. Nesse sentido, tanto as ações já realizadas quanto o projeto do memorial se colocam como formas simbólicas e terapêuticas de inscrição deste acontecimento.

\section{REFERÊNCIAS}

BIRMAN, J. Mal-estar na atualidade: A psicanálise e as novas formas de subjetivação. Civilização brasileira, 2005. Rio de janeiro.

BELAGA, Guillermo. La urgencia generalizada - ciencia, política y clínica del trauma. In: BELAGA, Guillermo (Org.). La urgencia generalizada 2: ciencia, política y clínica del trauma. Buenos Aires: Grama Ediciones, 2005. p.09-29.

FASSIN, D., \& RECHTMAN, R. The empire of trauma: inquiry into the condition of victimhood. Princeton: Princeton University Press, 2009.

FUKS, B. A cor da carne In Traumas, org. Ana Maria Rudge. São Paulo: Ed. Escuta, 2006. FREUD, S. Além do princípio do prazer in Obras Completas. Ed. Imago. Rio de Janeiro, ([1920]1995).

.Psicologia das massas e análise do Eu in Obras completas, Ed. Imago, Rio de Janeiro, ([1921]1995) 
LACAN, J. O Seminário. Livro 3: As psicoses. Rio de Janeiro: Jorge Zahar Ed. ([19551956]1988)

. Função e campo da fala e da linguagem em psicanálise, in: Escritos. Rio de Janeiro: Jorge Zahar Ed., ([1953]1998), p.238-324.

LAURENT, E. O analista cidadão in A sociedade do sintoma: a psicanálise hoje. Rio de Janeiro: Ed. Contracapa, 2007, p.141-150.

.O trauma, generalizado e singular, in: http://www.encontrocampofreudiano.org.br|2014|02 retirado em 25|10|2018

SOLER, C. Os discursos tela in Retorno do exílio: o corpo entre a psicanalise e a ciência. Org. Alberti, S. e Ribeiro, M. C. Rio de Janeiro: Contra Capa, 2004 


\section{Volnei Antonio Dassoler}

Psicanalista, doutorando em Psicologia Social e Institucional (UFRGS); Mestre em Psicologia (UFSM); Membro da Associação Psicanalítica de Porto Alegre; Integrante do comitê gestor do Acolhe Saúde (serviço de atenção psicossocial da Secretaria de Saúde de Santa Maria (RS) destinado às pessoas afetadas pelo incêndio na Boate Kiss (2013-2016).

Orcid: http://orcid.org/0000-0002-4581-7415

E-mail: dassoler@terra.com.br 